\title{
Equity in density
}

\author{
J. S. Palmer \\ Louis Laybourne Smith School of Architecture and Design, \\ University of South Australia, Australia
}

\begin{abstract}
Current development plans for numerous Australian cities are founded within the premise of urban containment, encouraging redevelopment, infilling and densification of established activity nodes as a means of improved future urban sustainability. Such propositions of future urban form challenge the existing 'Australian Dream' of single-family home ownership and prompt the exploration of not only physical alternatives to current development but consideration of the subsequent influence on future urban social sustainability. With housing affordability at an all time low property ownership becomes a major component in a new social divide. In recognition of the intrinsic link between the physical and social aspects of sustainability this paper draws together a range of data and discussions on current higher density housing in Australia and speculations regarding the social impact of current urban containment policies. In doing so it aims to provide an overview of potential concerns related to social sustainability and equality to be addressed by developers and architects as these planning policies are implemented. This overview is seen as essential in the successful translation of planning policy to built urban form to ensure they are accepted by the broader community and maintain the potential to achieve intended environmental benefits.
\end{abstract}

Keywords: social equity, urban consolidation, higher density housing, housing affordability, Australia.

\section{Introduction}

The vast majority of Australian urban landscapes are composed primarily of single family dwellings located on individual allotments. Under the influence of post war government policies encouraging home ownership our cities progressed rapidly into surrounding landscapes and continue to do so. During the decades of expansion around eighty percent of households attained the Great Australian 
Dream of home ownership within ever expanding suburban environments. Coinciding with the rise in motor vehicle ownership and progressing more rapidly than the planning and implementation of services and infrastructure this expansion has generated a legacy of low density urban environments heavily reliant upon private transport. Numerous Australian cities have implemented policies or plans encouraging urban consolidation through containment boundaries and densification guidelines. The objective to reduce environmental impact and increase the sustainability of the city is well intentioned; the validity of this is heavily debated in relation to many particularities. Regardless of whether the assumptions relating to reduced vehicle and energy use in denser environments becomes a reality or if greater public transport use can be encouraged, it is inevitable higher density urban development proposed by current planning policies is to play an increasing role in the Australian urban environment. As is the case with any intervention in the man made or natural world these policies are likely to directly impact upon a number of other environmental, social and economic aspects of urban dwelling.

In recognition of the intrinsic link between the physical and social aspects of sustainability this paper is concerned with the impact urban consolidation may have on issues of social equity. With reducing housing affordability and increasing housing stress experienced in urban areas the potential negative impacts of consolidation must be considered to minimise social polarisation. By drawing together data on current higher density housing in Australia with speculations regarding the social impact of densification an overview of concerns related to social sustainability and equality in consolidation is provided as a means of ensuring current planning policies achieve their social sustainability objectives.

\section{Dream equity/housing affordability}

Continuing suburban expansion has allowed generations of Australians to achieve the Great Australian Dream of home ownership in a relatively stable property market. Access to affordable land at the cities peripheries has supported this trend and provided a degree of lifestyle choice across the property market. In recent years the traditionally high rates of home ownership have fallen, with many younger people finding it increasingly difficult to enter the market. It has been predicted that the current generation may be the last to realise the Great Australian Dream as the housing affordability index continues to rise in capital cities. Four of Australia's eight state and territory capitals register within the worlds 20 most unaffordable housing markets, with others categorised as 'seriously unaffordable' [1]. The New South Wales Department of Housing observes a real term increase in residential real estate value of $80 \%$ in the eight years to 2004, a rise significantly in excess of rises in household income. Such trends reduce access to home ownership and lead to increases in the number of households in the rental market typically characterised by a lack of tenure security.

The housing affordability debate in Australia is constructed around housing stress, providing observation of both the home ownership market and the 
growing rental market. Housing stress is defined by the National Housing Strategy 1991 as where housing costs are greater than $30 \%$ of disposable household income and income is in the bottom $40 \%$ of income distribution. Studies by various organisations have employed this definition to observe a range of housing markets and submarkets. Harding et al [2] estimate $8.8 \%$ of Australian households face housing stress. They demonstrate that approximately two thirds of households in housing stress are in the private rental market and approximately one quarter are home purchasers. Gabriel and Yates [3] observe these trends relative to household incomes to demonstrate housing stress is not isolated to lower income brackets, with approximately $16 \%$ being moderate income households. In relation to household type, smaller households are at greater risk of housing stress, with the highest risk group being sole parents [2]. The most affordable housing developments are often located on city fringes at considerable distances from services and transport, creating reliance upon private transport and offering a false economy. The financial and time costs of transport have increasing impact on both access to services and employment and social community infrastructure. Acknowledging such additional costs related to limited housing options further increases the rate and impact of housing stress in such areas.

In a nation traditionally dominated by home ownership this increase in housing stress and reduced access to the property market has significant social and economic impacts beyond those of shelter [4]. Woods [5] notes growing social, spatial and economic polarisation between "those who have attained or will attain home ownership and those who will spend their housing careers in private rental housing." The reducing number of households that can afford to purchase homes also leads to greater income disparity as government policy and taxation systems are keyed toward the property owner. Historically a portion of the nations low income households have been accommodated through social/public housing programs administered by the states; these programs generally provide secure leases and income based rents resulting in a sector which Harding et al show to be at little risk of housing stress. Such government funded programs have experienced significant decline as government policies have changed from housing provision to private rental housing support. Yates observes that the number of public housing homes has reduced by 30,000 over the past decade, requiring resources to be more tightly targeted to need, with social housing now aimed primarily at low income households with multiple disadvantage. This reduction in public housing is accommodated by low cost private rental dwellings. Woods notes that in Sydney such dwellings are becoming increasingly concentrated in "pockets of disadvantage", further exacerbating social exclusion and polarisation.

Federal and State governing bodies have established a range of centres and units within housing departments to tackle the housing affordability issue and some have set targets for housing stress reduction within given time frames. In doing so it is critical to consider the range of household types and tenures currently experiencing housing stress and recognise that a number of approaches will be required to address their diverse needs. A 2005 stakeholder forum 
identified these four main household groups "that cannot compete successfully in their local or regional market":

- $\quad$ low income households with multiple disadvantage

- low income households with short term needs- aiming to next life stage

- low income households with longer term needs- no future change anticipated

- $\quad$ intermediate households requiring assistance to home ownership. [4]

Currently such households, representing an ever increasing proportion of the population, have extremely limited housing and lifestyle choices available to them due to unaffordability driven by escalating property prices. The challenge to correct this situation is a formidable one, and it must be considered how this might be influenced by current planning policies which in themselves challenge the context of the Great Australian Dream.

\section{Existing high(er) density housing in Australia}

The dominance of the single family residence located on its own block has influenced the Australian perception of higher density and multi-unit housing. With the highest rate of multi-unit housing at 15\% Sydney, like other Australian cities, sees this dwelling type associated with public housing provision and the private rental market. Forster [6] notes that due to the common ambition of achieving the Great Australian Dream "other types of tenure and dwelling structure tended to be seen as inferior, temporary or marginalised forms of accommodation." The high rate of home ownership typical in the suburbs is not translated to higher densities, with multi-unit ownership rates half that of detached housing. [7]

Randolph [8] discusses two distinctly different multi-unit markets, one being the high income professional or retiree market with high levels of home ownership in sought after locations, the other comprising low-income households renting units in suburban areas. Bunker et al analysed data from higher density households in Melbourne, Sydney and Brisbane confirming many intuitive assumptions:

- the market is predominantly for rental: $55 \%$ rented (detached houses $14 \%)$

- lower rates of ownership: 31\% owned outright or being purchased (detached houses 81\%)

- $\quad$ higher rate of single person households: $46 \%$ (detached houses $15 \%$ )

- lower rate of children under 15 years: 12\% of population (detached houses $23 \%$ )

- lower household incomes, reflecting higher rate of single person households

- $\quad$ greater transience: $26 \%$ of occupants living at same address 5 years prior (houses $56 \%$ )

- $\quad$ higher rate of recent immigration: $15 \%$ living overseas 5 years prior (houses 3\%)

- $\quad$ lower rate of access to private vehicle [7] 
These statistics suggest higher density housing is currently occupied primarily by those people with least choice. Limited access to housing options will continue to be an increasing problem in Australia whilst the national housing affordability index remains at a record high. The potential benefits of higher density development in relation to the fostering of close-knit communities and increased civic involvement promised by urban consolidation is not consistently present in existing higher density urban developments, possibly due to the transitoriness of occupants. The pocketing, or isolation, of differing dwelling types into distinct regions limits occupants options as to move 'up' to a preferred housing type one is forced to be dislocated from ones existing community networks.

As the approval of multi residential housing developments continues to rise preferred modes of ownership and tenure must be considered in advance to ensure the sustainability of this housing sector; is a growth of existing conditions desirable? It is generally accepted that to maintain social sustainability any community requires a cross section of people with a mixed balance of tenures and social groups; as such, considerable revision of the design and composition of such housing should be undertaken prior to substantially extending its presence through urban consolidation.

\section{Consolidation and equity}

The land use and density patterns espoused by urban consolidation policies will inevitably influence housing affordability as land and infrastructure comprise significant components of development. Troy [9] suggests infrastructure savings of up to $44 \%$ through the reuse of land in established urban areas. Opponents suggest such savings are overestimated due to the higher cost of multi-unit construction and the upgrades of infrastructure required to accommodate 'over capacities'. Burton [10] predicts the result of urban consolidation will be reduced living space and a lack of affordable housing.

Urban planning policies assume falling household size and increased number of single person households will translate to an acceptance of higher density housing. When observing choices made by residents in both Melbourne and Sydney Yates [11] found "some evidence for the claim that acceptance of higher density dwelling is driven primarily by affordability considerations rather than preferences." Birrell et al [12] suggest " $(\mathrm{t})$ he main growth in household numbers will be amongst older households whose housing preferences currently favour detached housing." Randolph expresses concern consolidation policies have not considered who will choose to live in the proposed housing and predicts the policies will reinforce social segregation through household type. Supporting this argument Cox [13] observes that "Melbourne, which has long been a place where most people own their own homes, is poised to become a city of renters. This will not be a fairer and more prosperous city. ... Melbourne is poised for a yesterday of less affluence and greater social division." Increasing density assumes more Australian's will spend lengthy periods of time living in a housing type that has previously only been a minority choice or a useful stepping stone to suburban home ownership. Birrell et al observe that following the recent 
property boom and the implementation of land supply restriction the majority of land releases are now aimed at 'trade-up' investors rather than the traditional first home buyer, further limiting options. They suggest "the Urban Growth Boundary is really about pushing the less well-off into high-density housing." [12]

Consolidation projects in areas of high home ownership are restricted by public objection to change often associated with concerns related to falling property values, congestion, crime and poor design [14]. Healey and Birrell [15] speculate that it is therefore unlikely the predicted numbers of dwellings allocated for the 'redevelopment and residential use of identified sites' in Melbourne and the 'filling up and infill of existing suburbs' in Sydney will be evenly distributed among regions of different socio-economic status. They suggest "there are already signs that urban consolidation is likely to be concentrated in areas of existing social disadvantage, where smart growth policies may exacerbate the processes of spatial inequality." The result of such distributions are variable; in some locations it is likely an increase in multi-unit private rental dwellings will be seen, escalating the current state of urban inequality. In other locations, such as inner or middle ring suburbs, it is likely the existing trend of gentrification through consolidation will continue to displace low income households from private rental properties as land holders exploit increasing property values for maximum return. Large scale regeneration of existing urban centres results in increased local property values and increased housing demand. As such rents are increased, the proportion of affordable rental properties reduced and social capital lost as connections between people and urban networks are severed. [14] In each of these scenarios the greatest impact of change is felt by the communities most needy and housing stress is increased over all income ranges. Increasing rates of homelessness due to urban consolidation are predicted and can be anecdotally observed.

The Melbourne 2030 plan states consolidation "should not exacerbate housing affordability problems" and that a "significant proportion of new development... must be affordable for households on low to moderate incomes..." [16] yet programs or resources to ensure affordable development are not substantially clarified. The formation of regional housing working groups within local government structures is proposed and affordability monitoring is mooted but without specific models or policies to work with it is unlikely under resourced regional working groups will make impact upon this increasingly national issue.

Where affordable housing mandates exist within regional or local development plans, such as the South Sydney City Council Green Square development, the provision of affordable dwelling units by the developer receives planning bonuses. Dwellings are transferred to non-profit Community Housing Organisations for rental to low income households. While these systems assist in maintaining diversity in urban renewal areas and provide secure tenure they do not increase the opportunity for affordable home ownership within the local community. This tendency to focus upon alternative funding and procurement for affordable rental accommodation is common across many states and joint ventures with developers are becoming increasingly common as a 
means of delivering social housing. The rate of development through such ventures falls short of replacing outdated public housing stock and therefore continues to be directed toward low income high need households. Beer [17] identifies planning bonuses as the most acceptable of a range of possible proactive planning interventions but questions their ability to provide affordable housing at the scale required to achieve significant change. Such mandates also fail to consider the identified range of households experiencing housing stress.

It is essential for a range of affordability options be made available to the market and that they be as diverse as the households they are tailored to serve. Considering established needs the priorities to be addressed in the execution of urban consolidation housing include:

- $\quad$ capital provision of social/public housing for low income households,

- $\quad$ mechanisms to ensure minimal housing stress in private rental and

- $\quad$ programs to ensure access to home ownership for low and moderate income households

The first of these priorities may be addressed with the expansion of planning bonuses, alternative financing schemes such as government housing bonds encouraged by Shelter NSW, or other private investment mechanisms. Importantly, the provision of social/public housing is not able to be implemented through planning mechanisms alone. Planning policy is even less able to respond to the latter two priorities which remain under the direct influence of the property market and development / investment processes. Beer concludes "unwieldy planning systems add to the cost of housing for all groups within society, and especially those who can least afford additional charges...planning does not have the capacity to deliver affordable housing opportunities in large volumes..." He suggests greater opportunities exist in alternative forms of housing finance, which increasingly features in affordability discussions. Financing options related to private rental housing are explored by Berry et al [18], a range of tax incentives are detailed which commonly provide landlords with financial benefits for properties rented to low income households or through community housing organisations. They explore also share equity as a means to home ownership, a model which has received interest from a number of state government affordable housing programs. In conclusion Berry et al suggest a range of possible approaches for future funding policies which aim to cover the diversity of household types and tenures currently affected by housing stress. Regardless of the method of funding these proposals continue to support the exiting methods of building design and construction without questioning the relationship between market demand and supply. Affordability and social equity has to date been sought through planning policy and financing methods with little consideration of the financial link to building design and construction processes.

\section{Design, construction and equity}

Projects pursuing the affordable Great Australian Dream undertaken by Landcom in New South Wales and VicUrban in Victoria, to name just two, have 
met with varying degrees of success. Common to such projects is the challenging of perceived demand in a developer driven market. The engagement of architects and increased emphasis on design quality broadens options where choices are typically limited by the developer and market perception of housing demand and excessive housing size is increasingly common. The influence of developer investment decisions on urban form and affordability is significant; once the formula for highest financial return is established in any given location it is repeated with minimal variation. Current multi-unit procurement methods typically involve the design of dwellings by developers and/or architects which are then offered for sale prior to or during construction, removing opportunity for occupant involvement in design. The result is a homogenous environment meeting the needs of the developer and the target household type but failing to accommodate variation in response to differing households or alternate preferences. The typical target market for recent multi-unit consolidation projects in Australian capital cities has been double income childless households. As a consequence low to moderate income households are either priced out of home ownership in these developments or are placed in considerable housing stress. To meet the needs of diverse households and facilitate acceptance of multi-unit dwelling as the New Australian Dream greater occupant involvement in the design process is required.

The majority of multi-unit developments involve the purchase of completed dwellings with the purchase price including significant contributions to developer profits and influenced by the vagaries of the property market. Ideally a home buyer would have the option of a range of procurement methods. Projects of the scale of 4-12 dwellings are common in consolidation projects and offer the opportunity for owner rather then developer led construction. With appropriate legal and financial mechanisms in place a collective of home buyers would make considerable savings through group design and construction. Interaction with group members through the design and construction process facilitates the erasure of definitive boundaries present in suburban developments, creating common features and facilities. The division of larger residential consolidation projects in designated activity centres into portions manageable by such groups places the final outcomes of local regeneration into the hands of the community rather than being controlled by faceless developers.

Where purchasers do not wish to be involved in design processes alteration to existing procurement is possible through 'shell' construction where purchasers complete the interior fit-out not only to their own taste but also within their own budget restrictions and without developer add-ons. Modification of typical multiunit design and construction is required to ensure the two stages of construction are appropriately managed. With mechanisms in place for building certification at completion 'shell' construction provides reduced risk to both the builder and the purchaser.

Involvement in the early stages of project development not only enables individuals to influence their personal living environment in line with their household needs and finances but also increases a sense of ownership in the area and commitment to the community, reducing transience. To facilitate these 
design and construction options and enable households to gain access to this New Australian Dream, legal frameworks and support services need to be introduced including:

administration units to facilitate formation of collectives and assist with legalities of the design and construction process, and

building certification programs recognising the distinction between shell and fit-out constructions.

Simplifying processes and creating market ready products enables maximum uptake.

\section{Equity versus density or equity in density}

To ensure current planning policies are implemented in an equitable and affordable fashion responsible agencies will need to ensure a range of higher density housing product is delivered that encourages wider social mix and greater social acceptance of this form of housing. This will include consideration of the following:

Appropriate distribution of consolidation developments, in areas of residential demand with existing community services.

The pursuit of social diversity in redeveloped centres

Pursuit of affordable housing initiatives which provide greater housing choice and tenure options, reducing the rates of private rental tenancies

Implementation of procurement methods providing residents an opportunity to be involved in the formulation of design strategies and community appropriate solutions rather being developer and profit driven

Such initiatives and processes exist beyond the reach of planning policy. Without substantial intervention to provide alternative opportunities within the current financially driven market the potential exists for urban consolidation policies to reinforce and exacerbate current inequalities within the higher density housing market in Australia. However, it is not inevitable.

Consolidation planning policies place great confidence in the power of design to deliver reductions in urban energy use, increased acceptance of densification, altered transport use patterns and social diversity. However 'over neat' [6] this vision may be, the policies do slow the peripheral growth of cities and offer the opportunity for improved urban sustainability compared to the status quo of external expansion. The Melbourne 2030 strategy admits 'the planning system is not well equipped' to address equity and affordability requirements. The ideal visions of social diversity, mixed tenure, housing variety etc. frequently discussed in relation to sustainable and equitable community design are not incompatible with urban consolidation but are unlikely to eventuate without support mechanisms in place to protect existing social capital and promote diversity in future growth. Current planning policies provide a framework into which rejuvenated housing, funding and construction policies can be nested to create potential for equity in density. 


\section{References}

[1] Demographia International Housing Affordability Survey: 2006 www.demographia.com

[2] Harding, A., Phillips, B. \& Kelly, S. Trends in Housing Stress, National Centre for Social and Economic Modelling, University of Canberra, 2004.

[3] Gabriel, M. \& Yates, J. Housing Affordability in Australia, Background Paper 3, Collaborative Research Venture for lower-income Australians, Australian Housing and Urban Research Institute (AHURI), Melbourne, 2005.

[4] Milligan, V. Directions for affordable housing policy in Australia: Outcomes of a stakeholder forum. AHURI, July 2005.

[5] Woods, G. What Is Happening In Australian Housing Markets? Why Policy Makers Should Be Concerned, Oswald Barnett Oration, 9 November 2004.

[6] Forster, C. The Challenge of Change: Australian Cities and Urban Planning in the New Millennium. Geographical Research, 44(2), pp.173182. June 2005.

[7] Bunker, R., Holloway, D., \& Randolph, B. Separating Prospects from Propaganda in Urban Consolidation. City Futures Research Centre, Faculty of the Built Environment, University of New South Wales.

[8] Randolph, B. Urban Renewal: a new role for new housing providers in creating sustainable communities? City Futures Research Centre, Faculty of the Built Environment, University of New South Wales. Issues Paper January 2006.

[9] Troy, P.N., The Perils of Urban Consolidation, Federation Press, Sydney, 1996.

[10] Burton, E. The compact city: just or just compact? a preliminary analysis, Urban Studies 37 (11), pp. 1969 - 2001, 2000.

[11] Yates, J. The rhetoric and reality of housing choice: the role of urban consolidation, Urban Policy and Research 19 (4), pp. 491-527, 2001.

[12] Birrell, B., O'Connor, K., Rapson, V. \& Healy, E. The Urban Growth Boundary Melbourne 2030, Monash University Epress, 2005.

[13] Cox, W., Melbourne 2030: A Vision Far Too Timid, The Public Purpose, Number 86, March 2005.

[14] Ohlin, J. A Suburb too Far? Urban Consolidation in Sydney, Briefing Paper for the New South Wales Parliament, April 2003. www.parliament.nsw.gov.au

[15] Healey, E. \& Birrell, B. Housing and Community in the Compact City, Positioning Paper, Melbourne Research Centre, AHURI, 2004.

[16] Department of Infrastructure Victoria, Melbourne 2030: Planning for Sustainable Growth. Department of Infrastructure, Melbourne, 2002.

[17] Beer, A., Housing Affordability and Planning in Australia, Housing Studies Association Conference, Belfast 2004.

[18] Berry, M., Whitehead, C., Williams. W. \& Yates, J., Financing Affordable Housing: A critical comparative review of the United Kingdom and Australia, AHURI, Sydney, November 2004. 